\title{
ANALYSIS OF COLLECTION MANAGEMENT PRACTICES IN ESA UNGGUL UNIVERSITY LIBRARY
}

\author{
Andi Khaerun Nisa ${ }^{1}$ \\ ${ }^{1}$ Pustakawan STIE AMKOP Makassar \\ Correspondence email: nisaandikhaerun@gmail.com
}

\begin{abstract}
The practices of collection management at the Esa Unggul University Library is still being distorted. There are several cases of collections that should have been weeded but still maintained which are the limitations of human resources to make the process to be inhibited and inefficient, budgeting, and space in the library so that the procurement of new bookshelves is still delusion. The data were obtained through observation, interview with librarians and from the official website of Esa Unggul University Library. The practices of collection management at Esa Unggul University Library, including: deselection, preservation and conservation, and storage. The deselection practice is scheduled every year. The preservation and conservation practices are carried out by termite and bookbinding methods on books, while for the electronic collections by duplicating files. Storage practices, Mezanin's shelf as a special space for old and copied books.
\end{abstract}

Keywords: Collection management; deselection; preservation; conservation; storage

\begin{abstract}
Abstrak
Pengelolaan koleksi di Perpustakaan Universitas Esa Unggul dalam praktiknya masih terjadi distorsi. Ada beberapa kasus koleksi yang seharusnya sudah disiangi namun tetap dipertahankan, keterbatasan SDM membuat prosesnya menjadi terhambat dan tidak efisien, dan karena keterbatasan anggaran dan ruang di perpustakaan sehingga pengadaan rak buku baru masih sebatas angan-angan. Data dikumpulkan melalui observasi, wawancara kepada pustakawan dan dari hasil studi dokumen pada website resmi Perpustakaan Universitas Esa Unggul. Praktik pengelolaan koleksi di Perpustakaan Universitas Esa Unggul, meliputi: praktik deseleksi, preservasi dan konservasi, dan storage. Praktik deseleksi dilakukan secara terjadwal yakni setiap tahun. Praktek preservasi dan konservasi dilakukan dengan metode umpan rayap dan penjilidan pada buku, sedangkan untuk koleksi elektronik dilakukan penggandaan file. Praktek storage, Rak Mezanin sebagai tempat penyimpanan khusus koleksi buku lama dan buku fotocopy.
\end{abstract}

Kata kunci: Manajemen koleksi; deseleksi; pelestarian; konservasi; penyimpanan 


\section{Pendahuluan}

Setiap perpustakaan memiliki visi dan misi yang berbeda dalam mencapai tujuannya. Adapun tujuan perpustakaan yaitu: penyimpanan, penelitian informasi, pendidikan, dan kultural (Sulistyo-Basuki, 1993). Salah satu aspek penting dalam mencapai tujuan perpustakaan adalah tersedianya koleksi yang sesuai dengan kebutuhan informasi pemustakanya. Oleh karena itu, diperlukan pengelolaan koleksi untuk mengatur dan mengorganisasi koleksi sehingga dapat dengan mudah diakses oleh pemustaka di masa sekarang dan yang akan datang. Perpustakaan perguruan tinggi sebagai penunjang tri dharma perguruan tinggi diharapkan dapat menjadi sarana penyedia informasi dalam proses pembelajaran dan penelitian bagi seluruh civitas akademika.

Menjelang pertengahan abad ke-20, beberapa perpustakaan akademik dan penelitian menangani ruang terbatas dengan membangun fasilitas penyimpanan di luar lokasi. Perpustakaan menempatkan bahan dalam penyimpanan karena mereka tidak memiliki cukup ruang koleksi di fasilitas utama mereka atau ingin membebaskan ruang koleksi untuk tujuan lain namun ingin menyimpan barangnya. Bahan yang jarang digunakan, serta yang membutuhkan perlindungan khusus, dipindahkan ke tempat penyimpanan. Memilih dan mengolah bahan untuk penyimpanan adalah pekerjaan intensif. Anggota staf di seluruh perpustakaan terlibat. Pustakawan pengelolaan koleksi menentukan kriteria dan bahan review. Bahkan dengan kriteria yang paling logis dan dapat dipertahankan, penilaian yang tepat sangat diperlukan. Seorang pustakawan atau petugas komunikasi dari perpustakaan perlu menyiapkan dan menyebarluaskan komunikasi kepada stakeholders. Staf layanan teknis mengubah lokasi pada catatan bibliografi dan menandai barang untuk penyimpanan. Bahan ditarik dari tumpukan dan diangkut ke lokasi baru. Kontrol fisik di lokasi penyimpanan membutuhkan sistem pencarian dan pengambilan. Ini mungkin melibatkan pembuatan katalog paralel dan memberi tanda tambahan pada item.

Pengelolaan koleksi adalah istilah umum yang mencakup semua keputusan yang dibuat setelah sebuah item merupakan bagian dari koleksi (Johnson, 2014). Istilah ini dipakai untuk menggantikan istilah pengembangan koleksi di era digital. Pengelolaan koleksi menurut Prytherch (Santi, 2010) adalah pengorganisasian dan pembinaan yang mencakup prinsip-prinsip pengembangan koleksi, pemenuhan kebutuhan-kebutuhan para pengguna sebagai tujuan utama, mengusahakan cara alternatif pemerolehan dokumen dan informasi guna melengkapi koleksi yang telah ada. Adapun praktik pengelolaan koleksi menurut Johnson (2014) yaitu; 1) Deseleksi atau penyiangan adalah proses menghilangkan bahan dari koleksi aktif untuk penarikan atau pemindahan (Rahayu \& Rahmah, 2013), (O'Neill, 2016), \& (Sujana, 2011), 2) Preservasi dan Konservasi, memperpanjang keberadaan bahan perpustakaan dan arsip dengan mempertahankannya dalam kondisi yang sesuai untuk digunakan, baik dalam format aslinya atau dalam bentuk yang lebih tahan lama, melalui retensi dalam kondisi lingkungan atau tindakan yang dilakukan setelah sebuah buku atau koleksi rusak untuk mencegah kerusakan lebih lanjut (Reitz, 2004), (Putra \& Marlini, 2013), \& (Sawant, 2014), dan 3) Storage atau area 
penyimpanan adalah lokasi di dalam fasilitas arsip atau perpustakaan, atau di luar dindingnya, yang jarang digunakan bahan dan peralatannya disimpan sampai dibutuhkan.

Meskipun banyak praktik yang baik dalam pengelolaan koleksi, namun terkadang juga mengalami kekacauan dalam pelaksanaannya. Praktik ini sering menjadi kritis karena kondisi, keterbatasan anggaran atau ruang, atau pergeseran dalam komunitas pengguna perpustakaan dan prioritas organisasi induk. Pengelolaan koleksi juga seringkali lebih bersifat politis daripada pengembangan koleksi. Komunitas pengguna, badan administratif, dan badan pendanaan mungkin curiga dengan disposisi material yang telah dikeluarkan. Beberapa produk dalam kegiatan preservasi terkadang kurang nyaman digunakan. Memutuskan koleksi mana saja yang harus dipertahankan dan disiangi menjadi tantangan perpustakaan. Memindahkan koleksi ke tempat penyimpanan jarak jauh seringkali menghambat akses dan membuat pengguna merasa frustrasi. Masa depan kurasi terkoordinasi pada fasilitas penyimpanan sangat kompleks dan tidak pasti (Johnson, 2014).

Perpustakaan Universitas Esa Unggul pun tidak luput dari permasalahan di atas. Pada pengelolaan koleksi yang meliputi, deseleksi, preservasi dan storage, dalam praktiknya masih terjadi distorsi. Pada praktik deseleksi, ada beberapa kasus koleksi yang seharusnya sudah disiangi, namun tetap dipertahankan. Kemudian pada praktik preservasi dan konservasi, keterbatasan SDM yang membuat proses praktiknya menjadi terhambat dan tidak efisien. Selanjutnya pada praktik storage, karena keterbatasan anggaran dan ruang di perpustakaan sehingga pengadaan rak buku baru masih sebatas angan-angan.

Perpustakaan Universitas Esa Unggul merupakan salah satu perpustakaan perguruan tinggi swasta di Jakarta. Saat ini, Perpustakaan Universitas Esa Unggul memiliki 31.959 koleksi, yang terdiri dari koleksi tercetak, meliputi: buku, artikel, jurnal, majalah, prosiding, laporan, modul, skripsi, tesis, dan disertasi. Sedangkan koleksi non-cetak (elektronik), meliputi: e-book, e-article, e-journal, CD yang berisi karya ilmiah mahasiswa (tesis, skripsi, disertasi), dan e-resource yang dilanggan oleh Perpustakaan. Dari sinilah penulis tertarik untuk mengidentifikasi praktik pengelolaan koleksi di Perpustakaan Universitas Esa Unggul.

\section{Metode}

Penelitian ini menggunakan metode penelitian kualitatif. Penelitian kualitatif adalah proses penyelidikan yang menarik data dari konteks di mana peristiwa terjadi, dalam upaya untuk menggambarkan kejadian ini, sebagai alat untuk menentukan proses di mana peristiwa disematkan dan perspektif mereka yang berpartisipasi dalam kejadian tersebut, dengan menggunakan induksi untuk mendapatkan penjelasan yang mungkin berdasarkan fenomena yang diamati (Gorman \& Clayton, 2005). Pengumpulan data diperolah melalui observasi, wawancara Bersama empat orang informan (pustakawan) dan dokumentasi yang tersedia di website perpustakaan (Creswell, 2014). 


\section{Hasil Penelitian}

\section{a. Deseleksi}

Pengelolaan koleksi adalah istilah umum yang mencakup semua keputusan yang dibuat setelah item merupakan bagian dari koleksi. Pada praktik pengelolaan koleksi, terkadang juga mengalami kekacauan dalam pelaksanaannya. Berkaitan dengan hal itu, penulis akan mendeskripsikan praktik pengelolaan koleksi di Perpustakaan Universitas Esa Unggul yang meliputi deseleksi, preservasi dan konservasi, dan storage (Johnson, 2014), yang penulis jabarkan seperti berikut ini:

Jenis koleksi di Perpustakaan Universitas Esa Unggul terdiri dari koleksi tercetak dan non-cetak (elektronik). Untuk koleksi tercetak, yaitu pada koleksi buku, praktik deseleksi telah dilakukan secara terjadwal yakni setiap tahun. Ada dua kriteria yang mereka gunakan pertama, frekuensi peminjamannya selama kurun waktu 3 tahun. Jika tidak pernah dipinjam pihak perpustakaan akan menariknya dari peredaran. Kedua keadaan fisik dari buku tersebut. Pada buku dengan keadaan fisik yang sangat parah pustakawan akan menarik dari peredaran.

"Namun, akan berusaha diadakan lagi dengan buku yang sama persis atau jika buku tersebut sudab tidak terbit lagi, maka akan diganti dengan subjek yang sama." (Aurora)

Untuk buku yang fisiknya rusak akan diusahakan pengadaan baru dengan cara memasukkan sebagai berkas desiderata untuk pengadaan tahun berikutnya. Kriteria lain mengenai praktik deseleksi, yaitu larangan dilayankannya buku fotocopy di perpustakaan oleh Rektor Universitas Esa Unggul.

"Kebijakan ini sudah diikuti tetapi masih sambil berproses, jika ada buku fotocopy yang ternyata sudah tidak diterbitkean lagi buku aslinya dan buku itu adalah satu-satunya yang dimiliki oleh perpustakaan, maka dengan berat hati buku tersebut tidak akan disiangi, hal ini menjadi kendala yang dihadapi oleh pustakawan.” (Rapunzel)

Untuk buku fotocopy yang buku aslinya sudah tidak terbit lagi, dapat diusahakan dengan pengadaan buku dengan subjek yang sama. Selain itu, pustakawan juga meminta kebijaksanaan kepada pihak Universitas mengenai keadaan tersebut. Untuk koleksi terbitan berseri, yaitu pada jurnal dan majalah, praktik deseleksi juga telah dilakukan secara terjadwal yakni setiap tahun.

"Tetapi tidak semuanya yang disiangi koleksi 3 tahun terakhir, ada jurnal dan majalah tertentu yang disiangi 5 tahun terakhir dan jika di rak sudab penub dan tidak memungkinkan untuk di display, yaitu pada jurnal hibah rutin, misalnya jurnal Media Keuangan. Adapun pada koleksi majalah, yaitu majalah Komisi Yudisial." (Yasmin)

Untuk koleksi terbitan berseri, seharusnya praktik deseleksinya tidak dibedakan jangka waktunya terbitannya karena jumlah rak yang terbatas. Untuk koleksi elektronik, Perpustakaan Universitas Esa Unggul tidak melakukan praktik deseleksi, karena jumlah koleksinya masih sedikit dan terbatas. 
"Sedangkan pada koleksi elektronik, tidak diadakan penyiangan namun diusahakan untuk ditambah apalagi menjelang proses akreditasi." (Yasmin)

Perpustakaan Universitas Esa Unggul sebaiknya menambah jumlah koleksi elektroniknya dengan proses digitalisasi buku dan pengadaan e-resources.

Ada beberapa kendala yang dihadapi pustakawan dalam praktik deseleksi yaitu: terjadi pergolakan batin antara kebijakan deseleksi yang telah ditentukan oleh perpustakaan dengan rasa tidak enak hati kepada pihak tertentu terkait dengan buku yang akan disiangi, kurangnya SDM, dan adanya ketidakseragaman standar Universitas Esa Unggul pada format fisik karya ilmiah mahasiswa (skripsi, tesis dan disertasi) yang kemudian menghambat proses deseleksi.

"Karena sekarang sudah ada repositori Universitas Esa Unggul, sehingga mahasiswa tidak perlu repot-repot mencari koleksi fisiknya, tapi dapat langsung mengaksesnya ke repositori." (Aladdin)

Seharusnya ada peraturan yang jelas dari pihak Universitas mengenai standar penulisan karya ilmiah mahasiswa, misalnya membuat Buku Pedoman Penulisan Karya Ilmiah.

\section{b. Preservasi dan Konservasi}

Praktik preservasi dan konservasi koleksi tercetak di Perpustakaan Universitas Esa Unggul, dilakukan dua jenis kegiatan, yaitu: pertama, mencegah kerusakan buku oleh rayap dengan metode umpan rayap. Kedua, penjilidan pada buku yang dilakukan secara mandiri dan manual oleh pustakawan.

"Sejak awal pada proses pengadaan koleksi semua buku harus disampul plastik, karena dulu ketika belum disampul, banyak buku yang cepat rusak. Memang membutubkan biaya yang lebih besar karena plastik harganya mahal. Namun, semenjak buku disampul, tingkat kerusakan buku jadi berkurang. Selain itu, ketika proses penjilidan dikerjakan oleh pustakawan sendiri, hasilnya jadi lebih bagus dan lebih ekonomis dibandingkean jika dikerjakan di tempat fotocopy, sehingga anggaran perpustakaan juga tidak banyak untuk kegiatan ini." (Aurora)

Meskipun proses penjilidan buku yang dilakukan secara mandiri dan manual hasilnya lebih bagus dan ekonomis, namun jika buku yang harus dikerjakan jumlahnya banyak, tentunya akan sangat tidak efisien. Seharusnya ada alat khusus yang dapat memudahkan pustakawan dalam pengerjaannya.

Pustakawan di Perpustakaan Universitas Esa Unggul juga melakukan kegiatan ini dalam praktik preservasi dan konservasi:

- Memperhatikan kebersihan perpustakaan termasuk debu pada rak buku.

- Menjaga kelembaban udara di ruangan koleksi.

- Mengatur cahaya ruangan koleksi.

- Melakukan alih bentuk pada koleksi yg rusak. 
"Sejaub ini, pustakawan telah berupaya melakukan segala kegiatan berkaitan dengan praktik preservasi dan konservasi di perpustakaan semaksimal mungkin sesuai standar perpustakaan." (Yasmin)

Pustakawan diharapkan dapat menjaga dan mempertahankan upaya dalam praktik preservasi dan konservasi di Perpustakaan Esa Unggul agar koleksi selalu terjaga dan layanan perpustakaan dapat berjalan dengan baik. Praktik preservasi dan konservasi pada koleksi elektronik yang meliputi koleksi karya ilmiah mahasiswa (skripsi, tesis, dan disertasi), dilakukan dengan penggandaan file koleksi. Adapun koleksi jurnal dan majalah elektronik, filenya untuk sementara hanya di CD-kan.

"Hanya saja disimpan di lemari tertutup khusus penyimpanan CD jurnal dan majalah elektronik, supaya terbindar dari hal-hal yang bisa membuat kepingan CD lembab." (Aurora)

Sejauh ini, memang belum ada kasus kerusakan pada file CD di Perpustakaan Universitas Esa Unggul, namun alangkah baiknya untuk mengantisipasi kerusakan yang sewaktu-waktu dapat terjadi, maka perlu dilakukan penggandaan file koleksi.

Kendala yang dihadapi Perpustakaan Universitas Esa Unggul dalam praktik preservasi dan konservasi adalah kurangnya SDM di perpustakaan, sehingga proses penjilidan buku masih dilakukan secara mandiri dan manual oleh pustakawan. Oleh karena itu, dibutuhkan alat press buku dengan desain khusus yang sesuai kebutuhan untuk memudahkan dalam proses penjilidan buku.

"Kalaupun ingin mengusulkan pengadaan alat itu di perpustakaan akan terlalu rumit karena tidak tabu nama alatnya dan belinya dimana, karena alat yang dimiliki Perpustakaan Nasional RI merupakan hibah dari pemerintah Jepang." (Aurora)

Untuk pengadaan alat press buku, pustakawan terlebih dahulu mencari tahu nama alat itu kemudian dapat diusulkan sebagai berkas desiderata untuk pengadaan tahun berikutnya.

c. Storage

Selain rak-rak penyimpanan buku yang ada di setiap lantai perpustakaan dan penyimpanan koleksi elektronik pada repositori dan CD, di Perpustakaan Universitas Esa Unggul juga terdapat rak khusus yang dinamai Rak Mezanin yang berisi koleksi buku-buku yang tahunnya lama dan buku-buku fotocopy yang sudah jarang dipinjam. Jika ingin meminjamnya, harus dengan bantuan pustakawan karena pemustaka tidak diperbolehkan mengakses langsung ke rak tersebut.

"Pemustaka yang ingin meminjam koleksi di Rak Mezanin harus menunggu bantuan dari pustakawan untuk menjangkau koleksi tersebut dimana penempatan koleksinya ada di area yang tidak dapat dimasuki oleh pemustaka (staff area).” (Yasmin)

Rak Mezanin sebagai storage atau penyimpanan khusus bertujuan agar tidak terjadi penumpukan koleksi di rak buku biasa, apalagi melihat kondisi rak buku di lantai 1 Perpustakaan Universitas Esa Unggul sudah sangat penuh. 
Kendala yang dihadapi Perpustakaan Universitas Esa Unggul dalam praktik storage adalah minimnya anggaran perpustakaan untuk pengadaan rak baru.

"Untuk, mengusulkan pengadaan rak buku, masib dinantikan karena dianggap tidak. begitu penting dan banyak hal lain yang harus diutamakan, padahal koleksi semakin bertambah. Intinya kendala utamanya adalah masalah anggaran perpustakaan." (Aurora)

Selain masalah anggaran, perpustakaan juga terkendala oleh keterbatasan ruang koleksi di Perpustakaan Universitas Esa Unggul. Melihat kondisi ruangan yang sempit dan rak buku yang banyak, namun tetap harus menyisakan ruang baca bagi pemustaka. Sehingga keterbatasan ruang koleksi juga menjadi pertimbangan pihak Universitas dalam upaya pengadaan rak baru.

\section{Diskusi dan Kesimpulan}

Pada praktik deseleksi, Perpustakaan Universitas Esa Unggul melakukan kegiatan deseleksi secara terjadwal yakni setiap tahun. Ada dua kriteria yang mereka gunakan pertama, frekuensi peminjaman koleksinya selama kurun waktu 3 tahun dan jika sudah jarang dipinjam maka akan disiangi. Kedua keadaan fisik dari buku tersebut apakah masih layak untuk dilayankan atau tidak. Kriteria lain, yaitu larangan dilayankannya buku fotocopy di perpustakaan oleh Rektor Universitas Esa Unggul. Untuk koleksi elektronik, Perpustakaan Universitas Esa Unggul tidak melakukan praktik deseleksi, karena jumlah koleksinya masih sedikit dan terbatas. Ada beberapa kendala yang dihadapi pustakawan dalam praktik deseleksi yaitu: terjadi pergolakan batin antara kebijakan deseleksi yang telah ditentukan oleh perpustakaan dengan rasa tidak enak hati kepada pihak tertentu terkait dengan buku yang akan disiangi, kurangnya SDM, dan adanya ketidakseragaman standar Universitas Esa Unggul pada format fisik karya ilmiah mahasiswa (skripsi, tesis dan disertasi) yang kemudian menghambat proses deseleksi.

Pada praktek preservasi dan konservasi, Perpustakaan Universitas Esa Unggul melakukan dua jenis kegiatan, yaitu: pertama, mencegah kerusakan buku oleh rayap dengan metode umpan rayap. Kedua, penjilidan pada buku yang dilakukan secara mandiri dan manual oleh pustakawan. Selain itu, perpustakaan juga: memperhatikan kebersihan perpustakaan termasuk debu pada rak buku, menjaga kelembaban udara di ruangan koleksi, mengatur cahaya ruangan koleksi, melakukan alih bentuk pada koleksi yg rusak. Untuk praktik preservasi dan konservasi pada koleksi elektronik yang meliputi koleksi karya ilmiah mahasiswa (skripsi, tesis, dan disertasi), dilakukan dengan penggandaan file koleksi. Adapun koleksi jurnal dan majalah elektronik, filenya untuk sementara hanya di CD-kan. Adapun kendala yang dihadapi dalam praktik preservasi dan konservasi adalah kurangnya SDM di perpustakaan, sehingga proses penjilidan buku masih dilakukan secara mandiri dan manual oleh pustakawan. Oleh karena itu, dibutuhkan alat press buku dengan desain khusus yang sesuai kebutuhan untuk memudahkan dalam proses penjilidan buku.

Sementara pada praktik storage, di Perpustakaan Universitas Esa Unggul selain terdapat rak-rak penyimpanan buku yang ada di setiap lantai perpustakaan dan penyimpanan koleksi elektronik pada repositori dan CD, juga terdapat rak khusus 
yang dinamai Rak Mezanin yang berisi koleksi buku-buku yang tahunnya lama dan buku-buku fotocopy yang sudah jarang dipinjam. Jika ingin meminjamnya, harus dengan bantuan pustakawan karena pemustaka tidak diperbolehkan mengakses langsung ke rak tersebut. Rak Mezanin sebagai storage atau penyimpanan khusus bertujuan agar tidak terjadi penumpukan koleksi di rak buku biasa, apalagi melihat kondisi rak buku di lantai 1 Perpustakaan Universitas Esa Unggul sudah sangat penuh. Kemudian, kendala yang dihadapi Perpustakaan Universitas Esa Unggul dalam praktik storage adalah minimnya anggaran perpustakaan untuk pengadaan rak baru. Selain masalah anggaran, perpustakaan juga terkendala oleh keterbatasan ruang koleksi. Melihat kondisi ruangan yang sempit dan rak buku yang banyak, namun tetap harus menyisakan ruang baca bagi pemustaka. Sehingga keterbatasan ruang koleksi juga menjadi pertimbangan pihak Universitas dalam upaya pengadaan rak baru.

\section{Referensi}

Allen, M. (2010). Weed 'em and reap : the art of weeding to avoid criticism. Library Media Connection, 28(6), 32-33. Retrieved September 29, 2019, from search.ebscohost.com/login.aspx?direct $=$ true $\& \mathrm{db}=\mathrm{a} 9 \mathrm{~h} \& \mathrm{AN}=50728717 \&$ site $=$ ehost-live

Creswell, J. W. (2014). Research design : Qualitative and mixed methods approache. California: Sage Publication.

Gorman, G., \& Clayton, P. (2005). Qualitative research for the information professional (2nd ed.). London: Facet Publishing.

Johnson, P. (2014). Fundamental of collection development and management. Chicago: ala editions.

O'Neill, J. L. (2016). Weeding with ADDIE: Developing training for deselection at an academic library. Reference \& User Services Quarterly, 56(2), 108-115. Retrieved September 17, 2019, from https://search.proquest.com/docview/1860278442?accountid=17242

Putra, A. D., \& Marlini. (2013). Preservasi dan konservasi pustaka di Perpustakaan Proklamator Bung Hatta. Ilmu Informasi Perpustakaan dan Kearsipan, 1(2), 2431. Retrieved September 17, 2019, from http://ejournal.unp.ac.id/index.php/iipk/article/view/1088/926

Rahayu, A., \& Rahmah, E. (2013). Kegiatan penyiangan bahan pustaka (weeding) di Perpustakaan Universitas Negeri Padang. Ilmu Informasi Perpustakaan dan Kearsipan, 12-19. Retrieved September 17, 2019, from http://ejournal.unp.ac.id/index.php/iipk/article/view/2285

Reitz, J. M. (2004). ODLIS. Retrieved September 29, 2019, from ABC-CLIO: https://products.abc-clio.com/ODLIS/odlis_p.aspx

Santi, T. (2010). Manajemen koleksi (collection management) kebijakan pengembangan koleksi perpustakaan Perguruan Tinggi. Iqra', 04(01). Retrieved September 15, 2019, from http://library.iainsu.ac.id/journal/index.php/iqra/article/view/87 
Sawant, S. (2014). A study on preservation and conservation practices in academic libraries in Mumbai. Annals of Library and Information Studies, 61(2), 153-159. Retrieved September 29, 2019, from http://eprints.rclis.org/23424/

Sujana, J. G. (2011). Weeding : Membuat akses pada koleksi lebih baik. Jurnal Pustakawan Indonesia, 11(1), 15-20. Retrieved September 20, 2019, from http://journal.ipb.ac.id/index.php/jpi/article/view/5265

Sulistyo-Basuki. (1993). Pengantar ilmu perpustakaan. Jakarta: Gramedia Pustaka Utama. 